University of Nebraska - Lincoln

DigitalCommons@University of Nebraska - Lincoln

November 1989

\title{
Comparisons of cutoff and regression-based definitions of reading disabilities
}

\author{
J. M. Fletcher
}

K. A. Espy

University of Nebraska-Lincoln, kespy2@unl.edu

D. J. Francis

K. C. Davidson

B. P. Rourke

See next page for additional authors

Follow this and additional works at: https://digitalcommons.unl.edu/dcnlfacpub

Part of the Neurosciences Commons

Fletcher, J. M.; Espy, K. A.; Francis, D. J.; Davidson, K. C.; Rourke, B. P.; and Shaywitz, S. A., "Comparisons of cutoff and regression-based definitions of reading disabilities" (1989). Developmental Cognitive Neuroscience Laboratory - Faculty and Staff Publications. 28.

https://digitalcommons.unl.edu/dcnlfacpub/28

This Article is brought to you for free and open access by the Developmental Cognitive Neuroscience Laboratory at DigitalCommons@University of Nebraska - Lincoln. It has been accepted for inclusion in Developmental Cognitive Neuroscience Laboratory - Faculty and Staff Publications by an authorized administrator of DigitalCommons@University of Nebraska - Lincoln. 


\section{Authors}

J. M. Fletcher, K. A. Espy, D. J. Francis, K. C. Davidson, B. P. Rourke, and S. A. Shaywitz 


\section{Comparisons of Cutoff and Regression-Based Definitions of Reading Disabilities}

\author{
Jack M. Fletcher, K.A. Espy, David J. Francis, \\ Kevin C. Davidson, Byron P. Rourke, and Sally E. Shaywitz
}

This study addressed the issue of specificity in reading disability by comparing two approaches to defining and selecting children with reading disabilities. One approach defined reading disability according to cutoff scores representing appropriate levels of intelligence and reading deficiency, whereas the other approach adjusted these scores for their intercorrelation through regression procedures. Results revealed clear differences in which children were identified as reading disabled according to the two definitions. However, differences in neuropsychological performance between children whose reading scores were discrepant or not discrepant with $I Q$ were small and nonspecific for both definitions. The results of this study show that children identified as reading disabled vary according to the definition employed; at this point, there is little evidence suggesting any specificity of reading disability according to definition.

C areful analyses of the criteria used to define and select children with reading disabilities are urgently needed. There is a persistent tendency on the part of researchers and professionals working with this population to accept traditional definitions of reading disability based on consensus or professional opinion without examination of the assumptions or empirical characteristics of various definitions (Fletcher \& Morris, 1986). It is most common to define a child as reading disabled in the presence of a discrepancy between potential ability and the actual achievement of reading skills. Terms such as "dyslexia" and "specific reading disability" have been used almost interchangeably to refer to children with average levels of potential ability, poor reading skills, and an absence of problems due to cultural factors, instructional methods, and sensory or acquired neurological deficits. However, neither the labels nor the criteria for their operationalization have been subjected to extensive analyses of validity and reliability (Fletcher \& Morris, 1986; Rourke, 1983; Rutter, 1974). As Rourke (1983) suggested, these definitions have rarely emerged from empirical investigation.

The analysis of these criteria, a common enterprise in classification research, is necessary for any scientific endeavor addressed to subpopulations presumably sharing common phenotypic characteristics (Fletcher, Francis, \& Morris, 1988; Morris \& Fletcher, 1988; Rourke, 1983). Classification research should address the validity of definitions that are often implicit in describing a child as reading disabled. These definitions should be based on criteria that are explicit, public, and clearly operationalized. When criteria vary, subject characteristics change across studies, leading to intrasubject variability that obscures attempts at measurement of skills or studies of remediation (Doehring, 1978). Similarly, classification is the basis for a common nomenclature that must be explicit for accurate communication among professionals. Finally, it is difficult to interpret experimental research without careful specification of the independent variables. Regardless of how well a construct is measured (i.e., dependent variables), studies that don't specify carefully operationalized criteria for selecting subjects cannot be replicated and null results become difficult to interpret (Fletcher et al., 1988). Research on children with reading disabilities highlights the need for classification studies addressing the validity of commonly accepted definitions used to identify children as reading disabled (Fletcher \& Morris, 1986; Morris \& Fletcher, 1988; Rutter, 1974).

An example of these problems is the use of discrepancy-based definitions of reading disability. When children with reading problems are defined and selected according to discrepancies between intelligence and achievement $-\mathrm{a}$ common practice since the adoption of Public Law 94-142 - several problems emerge. One set of problems concerns the use of IQ tests to measure potential. A child's performance on IQ measures is influenced by past learning, genetic endowment, and a host of situational factors (Bortner \& Birch, 1980; Estes, 1981). In addition, the same cognitive problems that are present in children with reading problems also reduce scores on IQ tests. For example, a processing deficiency in language, which may be associated with reading problems, may also reduce verbal IQ scores (Taylor, Fletcher, \& Satz, 1984). Finally, IQ tests such as the Wechsler Intelligence Scale for Children- Revised (WISC-R) do not measure all aspects of a child's adaptive functioning, such as social behavior and more specific information processing skills (Guilford, 1967; Kaufman, 1979). Most IQ scores represent combined measurements of several covarying abilities - hardly a measure of a single construct called "potential." This is illustrated by the fact that IQ scores are correlated with school achievement in randomly selected groups of children, but have not been shown to be particularly predictive of achievement in children with reading disabilities (Sattler, 1982; Taylor et al., 1984).

The second set of problems is statistical and concerns the attempt to define learning disabilities by statistical comparisons of IQ and achievement standard scores. Such comparisons are apparent in eligibility legislation in most states and school districts across the United States. The statistical comparison of discrepancies between imperfectly correlated test scores is always associated with regression to the mean. Basically, regression to the mean results from the interdependence of imperfectly correlated measures. Practically, if scores on an IQ test and an achievement test are not corrected for their intercorrelation, there will be a tendency for scores on one test to move 
closer to an average score in the presence of an extreme score on the other test. For example, children with IQ scores 2 standard deviations above the mean will, on the average, have achievement scores less than 2 standard deviations above the mean (Yule, 1978).

It is possible to use regression procedures to define IQ-achievement discrepancies that correct for regression artifacts (Reynolds, 1984). However, even when scores are corrected, it is not clear that children with discrepancies in IQ and achievement have more specific disabilities than do poor achievers whose IQ scores are not discrepant. Rutter and Yule (1975) defined children with achievement problems according to whether they were "backward readers," who read at IQ-appropriate levels, or "specific reading disabled," who read below expected levels according to their IQ scores. To date, however, relatively little empirical evidence exists showing that similarly defined children differ on measures other than IQ (Morris \& Satz, 1986). Shaywitz, Shaywitz, Barnes, and Fletcher (1986) compared the influence of various definitions on the selection of children as learning disabled in an epidemiological study. Although variations in the use of IQ indices and definitions resulted in different children being identified as learning disabled, few differences in cognitive ability were apparent among children grouped as learning disabled according to various definitions. There were also few differences among children defined as learning disabled whose scores were discrepant or not discrepant with IQ.

In order to develop more adequate, empirically based definitions of reading disability, systematic analyses of the characteristics of various definitional criteria leading to the identification of children with reading disabilities must be completed. There is persistent interest in typologies of reading disabilities and other classification hypotheses (Rourke, 1985). However, research addressing the criteria for defining a disorder is a prerequisite to any search for subtypes, since the emergence of a typology will depend in part on how children are entered or excluded from the sample (Morris \& Fletcher, 1988). Different subtypes may emerge based on issues as simple as the IQ cutoff and achievement cutoff scores defining the sample.

The present study expands upon Shaywitz et al. (1986) by employing a large, clinic-based (but school-referred) sample in an attempt to study (a) the effects of variations in definitions and (b) whether differences in neuropsychological skills emerge between children whose reading skills are discrepant or not discrepant with IQ.

\section{METHOD}

\section{Subjects}

The children for this study were obtained from a data base of over 2,500 cases representing children referred for evaluation of learning disability in Windsor, Ontario. Each child received a comprehensive neuropsychological evaluation (Rourke, 1981; Rourke, Fisk, \& Strang, 1986), and the Wechsler Intelligence Scale for Children (WISC) (Wechsler, 1949) and the Wide Range Achievement Test (WRAT) (Jastak \& Jastak, 1965) were administered. For this study, children were selected ranging in age from 9 years to 14 years, with Full Scale WISC IQ scores above 79. These children were free of sensory, acquired neurological, and other problems traditionally used as exclusionary criteria, resulting in a total sample of 1,069 children. The sample, $74 \%$ of whom were male, were predominantly white, middle class children who averaged 11 years, 4 months in age, with a mean WRAT reading standard score of $89.3(S D=14.8)$ and mean WISC FSIQ of $98.5(S D=10.5)$.

\section{Procedures}

Two different definitions were used to identify children as reading disabled, based on the word recognition score from the WRAT and the WISC FSIQ. The first definition employed a cuttingscore approach that did not correct for regression artifact. Children were defined as reading disabled if their FSIQ exceeded 79 and their WRAT reading standard score was below 93. In addition, children were categorized according to whether reading scores were consistent with or inconsistent with FSIQ using a criterion of 15 points. A child was considered "dis- crepant" if his or her WRAT score was 15 points or lower than FSIQ. This definition corresponds directly with criteria used by the Texas Education Agency (TEA) and other states to define eligibility for reading disabilities services. Liberal criteria in terms of relative severity of word recognition deficit and IQ were used in the hope of capturing the largest possible sample unbiased according to selection variables.

\section{RESULTS}

Table 1 presents sample sizes for the resultant $2 \times 2$ matrix of children who were classified according to definition and IQ-reading discrepancies. Note that there is a small group of children $(n=36)$ with reading standard scores greater than 92 whose reading score was at least 15 points below FSIQ. The other children are distributed fairly evenly across the matrix. About $34 \%$ had reading standard scores below 93 that were at least 15 points below their FSIQ scores, with $30 \%$ regarded as not impaired in reading. Some $32 \%$ of the children exhibited poor reading and low average FSIQ, but would not qualify for services.

The second definition corrected for regression artifact inherent in the comparison of WRAT and WISC scores using a formula adopted by Shaywitz et al. (1986). This formula is a variation on those provided by Reynolds (1984) and corrects for the correlation of FSIQ and WRAT Reading in the specific population of interest. This formula also takes into account the nonuniform variability in predicted reading scores at different values of IQ. Using a comparable definition of discrepancy, Table 2 presents the resultant $2 \times 2$ matrix. It is apparent that the distribution of children across the four categories is different from that in Table 1. More children are identified as discrepant and fewer as nondiscrepant. In terms of overlap between the two definitions, 70 children (7\%) with reading standard scores below 93 become eligible for services using the regression-based definition who were not eligible under the cutoff score definition. These children were generally lower on FSIQ $(M=87.7 ; S D=4.5)$ and WRAT reading $(M=75.7 ; S D=3.4)$ than were 
the group of discrepant readers identified in the first analysis. However, $22(2 \%)$ children who had reading standard scores below 93 and 15-point discrepancies between IQ and reading were no longer eligible under the regression-based definition. These children had a mean WISC FSIQ of $106.2(S D=3.0)$ and mean WRAT reading standard score of 89.7 $(S D=3.0)$. Of the 36 higher-IQ-butdiscrepant achievement children eligible under the cutoff score criterion, only 5 remain eligible when the definition takes into account regression effects. Thus, the regression-based criteria make 70 "poor readers" eligible and eliminate eligibility for 22 children with word recognition scores below 93 but within the range expected given their IQ, and for 31 children with age-appropriate word recognition scores $(M=97.1 ; S D=3.6)$ and higher FSIQ $(M=114.6 ; S D=4.2)$.

\section{Effects of Variations in Definition}

A second set of analyses addressed whether variations in definition produced differences in ability structure among groups formed with different definitional criteria. To address this possibility, low achieving children who were discrepant and not discrepant under the two definitions were compared on a set of tests derived from a modification of the Halstead-Reitan Neuropsychological Battery for Children (HRB) (Rourke et al., 1986). These measures constitute a representative sample of neuropsychological skills and abilities that are ordinarily administered in a comprehensive evaluation of children with learning disabilities (Rourke, 1981). The linguistic and auditory-perceptual measures are especially sensitive to the reliable discrimination of children with reading disability from nondisabled children and from children with other types of learning disabilities (Rourke, 1978, 1981; Rourke et al., 1986).

Ten tests from the HRB were used. These tests are presented in Table 3 along with a summary of the constructs measured by each task. These constructs were defined according to recent maximumlikelihood factor analyses of the test battery in this sample completed by our group. It is apparent that these tests measure a variety of abilities frequently
TABLE 1

Distribution, Mean IQ, and Word Recognition Scores of Children Categorized According to Reading Standard Scores and Raw Discrepancies

Reading Standard Score

$\leq 92$

$>92$

$\begin{array}{lll}\text { Discrepant } & n=360(34 \%) & n=36(4 \%) \\ & \text { FSIQ }=101.8(8.7) & \text { FSIQ }=114.9(6.3) \\ & \text { RdSS }=78.4(8.0) & \text { RdSS }=96.1(5.1) \\ \text { Not Discrepant } & n=347(32 \%) & n=326(30 \%) \\ & \text { FSIQ }=90.6(6.0) & \text { FSIQ }=101.3(10.8) \\ & \text { RdSS }=83.9(5.7) & \text { RdSS }=106.4(12.2)\end{array}$

Note. FSIQ = Full Scale IQ on Wechsler Intelligence Scale for Children; RdSS = reading standard score on Wide Range Achievement Test.

\begin{tabular}{|c|c|c|}
\hline \multicolumn{3}{|c|}{$\begin{array}{l}\text { TABLE } 2 \\
\text { Distribution, Mean IQ, and Word Recognition Scores of Children Categorized } \\
\text { According to Reading Standard Scores and Regression-Based Discrepancies }\end{array}$} \\
\hline & \multicolumn{2}{|c|}{ Reading Standard Score } \\
\hline & $\leq 92$ & $>92$ \\
\hline \multirow[t]{3}{*}{ Discrepant } & $n=408(38 \%)$ & $n=5(1 \%)$ \\
\hline & $\mathrm{FSIQ}=99.2(9.8)$ & $\mathrm{FSIQ}=99.2(9.8)$ \\
\hline & RdSS = $77.3(7.2)$ & RdSS $=90.2(9.1)$ \\
\hline \multirow[t]{3}{*}{ Not Discrepant } & $n=299(28 \%)$ & $n=357(33 \%)$ \\
\hline & $\mathrm{FSIQ}=92.4(7.1)$ & $\mathrm{FSIQ}=102.5(11.0)$ \\
\hline & RdSS $=86.2(4.2)$ & RdSS $=105.6(12.0)$ \\
\hline
\end{tabular}

\section{TABLE 3}

Modified Halstead-Reitan Neuropsychological Tests by Factor Structure

\begin{tabular}{|c|c|}
\hline Test & Factor \\
\hline 1. Category Test & $\begin{array}{l}\text { Executive Functions, } \\
\text { Spatial Relations }\end{array}$ \\
\hline $\begin{array}{l}\text { 2. Speech-Sounds Perception } \\
\text { Test }\end{array}$ & $\begin{array}{l}\text { General Language } \\
\text { Acoustic Language }\end{array}$ \\
\hline 3. Auditory Closure Test & $\begin{array}{l}\text { General Language, } \\
\text { Acoustic Language }\end{array}$ \\
\hline 4. Sentence Memory Test & $\begin{array}{l}\text { General Language, } \\
\text { Acoustic Language }\end{array}$ \\
\hline 5. Verbal Fluency Test & $\begin{array}{l}\text { General Language, } \\
\text { Acoustic Language }\end{array}$ \\
\hline 6. Finger Tapping Test & Simple Motor \\
\hline 7. Grooved Pegboard Test & $\begin{array}{l}\text { Eye-Hand Coordination, } \\
\text { Spatial Relations }\end{array}$ \\
\hline 8. Tactual Performance Test & $\begin{array}{l}\text { Spatial Relations, } \\
\text { Executive Function, } \\
\text { Eye-Hand }\end{array}$ \\
\hline $\begin{array}{l}\text { 9. Trail Making Test, } \\
\text { Parts A and B }\end{array}$ & Executive Function \\
\hline 10. Target Test & $\begin{array}{l}\text { Spatial Relations, } \\
\text { Eye-Hand }\end{array}$ \\
\hline
\end{tabular}


impaired in children with reading disabilities, including language, perceptual, and motor skills.

All scores were converted to age standardized scores using available normative data. For each comparison of discrepant and nondiscrepant readers, the data were subjected to a linear discriminant function analysis with follow-up interpretation of the discriminant functions to determine variable contributions to group separation. Identification rates (i.e., proportion of children correctly placed into reading groups based on HRB tests) were computed as an estimate of effect size.

\section{Cutoff Versus Regression-Based Comparisons}

Table 4 summarizes the results of the comparison of discrepant and nondiscrepant poor readers on the $10 \mathrm{HRB}$ tasks using the two definitions. A significant discriminant function was obtained for each comparison: cutoff, $F(10,696)=20.1$, $p<.001$; regression, $F(10,696)=15.3$, $p<.0001$. In terms of variable selection, it is apparent that results are similar for both comparisons, with considerable overlap in those variables maximally separating the groups. In both comparisons, the Speech-Sounds Perception Test, a measure of acoustic language that involves recognition of the visual representations of aurally presented nonsense words, is the best discriminator. The basic difference in the two comparisons is the emergence of the Category Test (executive functions, spatial relations factors) as an important discriminator in the regression-based comparison, and the Target Test (spatial relations, eye-hand coordination factors) in the cutoff score comparison. For the cutoff score comparison, the nondiscrepant group was lower on all variables except for the Sentence Memory Test (rote language factor). In the regression-based comparison, the distinctions seemed more meaningful, with the discrepant group scoring lower only on the Speech-Sounds Perception Test (acoustic language factor) and the nondiscrepant group scoring lower on a variety of tasks involving concept formation and spatial relations. Identification rates of .69 in both analyses show that effect sizes are small but comparable.

\begin{tabular}{|c|c|c|c|c|}
\hline \multicolumn{5}{|c|}{$\begin{array}{c}\text { TABLE } 4 \\
\text { Comparisons of Standardized Discriminant Function Weights Maximally } \\
\text { Separating Discrepant and Nondiscrepant Children with Reading Disabilities } \\
\text { on Neuropsychological Tests }\end{array}$} \\
\hline \multirow{3}{*}{ Variable } & \multicolumn{4}{|c|}{ Definition } \\
\hline & \multicolumn{2}{|c|}{ Cutoff Score } & \multicolumn{2}{|c|}{ Regression-based } \\
\hline & Unadjusted & Adjusteda & Unadjusted & Adjusteda \\
\hline Category Test & .35 & .07 & .27 & .05 \\
\hline \multicolumn{5}{|l|}{ Speech Sounds } \\
\hline Perception Test & -.59 & -.14 & .78 & -.14 \\
\hline Auditory Closure Test & .10 & -.11 & .29 & -.19 \\
\hline Sentence Memory Test & .47 & .29 & -.39 & .34 \\
\hline Verbal Fluency Test & -.51 & .86 & -.03 & .87 \\
\hline Finger Tapping Test & .05 & .20 & .09 & .19 \\
\hline Grooved Pegboard Test & .36 & .16 & .34 & .10 \\
\hline Tactual Performance Test & .42 & .23 & .31 & .16 \\
\hline $\begin{array}{l}\text { Trail Making Test, } \\
\text { Parts A and B }\end{array}$ & .10 & .06 & -.06 & .08 \\
\hline Target Test & -.29 & -.05 & .33 & -.15 \\
\hline
\end{tabular}

\section{Influence of IQ, Age, and Achievement}

The $10 \mathrm{HRB}$ tests covary with IQ and age. Although all scores were age-corrected, we chose to covary age to eliminate any possible influence due to nonspecific sample characteristics that might have affected the applicability of the age norms first used to adjust scores. It was not apparent that covariation for age had significant influence on the results, so these results are not separately reported. Covariation for IQ was conducted to estimate the magnitude and nature of group differences when variability due to FSIQ scores was eliminated. The results of these discriminant function analyses are also summarized in Table 4 . The adjusted discriminant functions were significant: cutoff, $F(10,694)=9.5, p<.0001$; regression, $F(10,694)=14.3, p<.0001$. Three variables contributed to group separation in both analyses: Verbal Fluency, Sentence Memory, and Grooved Pegboard. The effect size (.65) is comparable to the unadjusted analyses (.69), showing that removal of IQ had little effect on the magnitude of group differences. The group profiles are similar in both analyses, with the discrepant group scoring lower on the Verbal Fluency Test (acoustic language factor) and the nondiscrepant group scoring lower on the Grooved Pegboard Test (eye-hand, spatial relations factors). These results show that removing IQ differences leads to a common set of discriminators between the two definitions, with no difference in effect size. Differences in variable weights across analyses generally reflect relationships of various measures with FSIQ, not group membership.

\section{DISCUSSION}

These analyses addressed two questions. The first question was the influence of different definitions of reading disability in terms of which children were identified as "reading disabled." The second question concerned differences on external variables between children with reading problems whose scores were discrepant or not discrepant with IQ-based expectations.

For the first question, these results show that variations in definitional criteria lead to differences in which children are designated as reading disabled. With a cutoff score approach, IQ score differences between discrepant and nondiscrepant children are larger, word recogni- 
tion score differences are smaller, and many lower IQ children are not identified as eligible for services. In contrast, more children become eligible for services when regression-based procedures are used, with some higher IQ, better reading children becoming ineligible. The IQ differences are negligible, but differences in word recognition scores are larger. Hence, one conclusion may be that use of unadjusted IQ-achievement discrepancies is biased against children who score lower on IQ tests.

In terms of the second question, differences between discrepant and nondiscrepant children on external variables are significant for both definitions, but are small, difficult to characterize, and tend to dissipate when IQ and age are used as covariates. The main influence of using a regression-based procedure is to more clearly polarize group differences on external measures (despite reducing IQ differences) by adding lower IQ children. The discrepant group displays lower performance than the nondiscrepant group only on measures of acoustic language. As such, the results are similar to those of Jorm, Share, MacLean, and Matthews (1986), who found that specific problems with phonological language discriminated a small group of poor readers with discrepancies in IQ and reading from a group of nondiscrepant poor readers.

It is possible that the regression-based definitions produce a more homogeneous group of poor readers. However, further research using measures more clearly related to reading proficiency may be necessary to elucidate these differences. Individual HRB tests are factorially confounded, measuring several different abilities. Some of these abilities may be related to reading disability and other abilities to some other less specific (but adaptive) characteristics of the child. Whether group differences between discrepant and nondiscrepant children would be clearer with other measures is an empirical question. However, given the small effect size and the heterogeneity of the groups, it is not likely that any other set of measures would produce clearer differences between the groups, particularly given the absence of any theoretical reason to expect group differences.

Eliminating variability due to age and IQ did not significantly alter effect size, but did alter the number and nature of discriminating variables. Since the scores were age-corrected, IQ was the principal covariate. The neuropsychological variables discriminated almost as robustly when IQ was eliminated from overall variability, showing that such measures capture variability not reflected in IQ tests (Taylor et al., 1984). However, the nature of group differences is quite similar between the two definitions. Additional research should address more precisely the role and contribution of IQ scores to definitions of reading disability. The fact that discrepant and nondiscrepant reading groups show very small differences when IQ is covaried implies that the IQ differences may not be important.

The results of this study demonstrate that the specificity of a reading disability depends in part on how it is defined. Sample constituents change when definitional criteria are varied. However, the notion that intelligence scores are determinants of reading proficiency or indices of potential is not supported by this study. IQ scores are actually lower when regression-based procedures are used, but the groups seem to become more homogeneous. The next step in this type of research would be systematic variation of other assumptions inherent in definitions of learning disabilities. For example, Shaywitz et al. (1986) explored various IQ cutoffs and the influence of varying levels of severity of reading (i.e., achievement cutoffs). Degree of discrepancy (1 $S D, 1.5 S D, 2 S D$ ) could be varied. In each instance, a set of external variables should be available to provide criteria for comparisons. Treatment outcomes would be especially relevant.

This type of classification research is straightforward, time-consuming, and perhaps to some, dry and boring. However, classification research of this type is fundamental to any scientific endeavor and essential to future progress in studying and remediating children with reading disabilities (Fletcher \& Morris, 1986). Determining the influence of variations in definitional criteria is a prerequisite for adequate understanding of the cognitive and biological correlates of reading disabilities. Statements about specificity and definition remain empirical questions in need of considerable research.

\section{ABOUT THE AUTHORS}

Jack M. Fletcher is an associate professor of psychology at the University of Houston in the clinical neuropsychology program. He is a diplomate of the American Board of Clinical Neuropsychology. His principal research areas are concerned with the classification of neurobehavioral disorders of childhood and with recovery of function in brain injured children. K.A. Espy is a graduate student in the Department of Psychology, University of Houston. David J. Francis, $P h D$, is an assistant professor, Department of Psychology, University of Houston. Kevin C. Davidson is a graduate student, Department of Psychology, University of Houston. Byron P. Rourke, $P h D$, is professor of psychology and university professor at the University of Windsor. He has co-authored and edited several books, including Child Neuropsychology: An Introduction to Theory, Research, and Clinical Practice. Sally E. Shaywitz, $M D$, is a developmental pediatrician, Department of Pediatrics, Yale University School of Medicine. She is interested in learning and attentional disorders in children. She is the principal investigator of the Connecticut Longitudinal Study. Address: Jack M. Fletcher, Department of Psychology, 4800 Calhoun Rd., University of Houston, Houston, TX 77004.

\section{AUTHORS' NOTES}

1. The research reported in this paper was supported in part by NICHD Grant No. HD-21888, Psycholinguistic and Biological Mechanisms in Dyslexia. 2. This paper was presented at the annual meeting of the American Educational Research Association, New Orleans, April 6, 1988.

\section{REFERENCES}

Bortner, M., \& Birch, H.G. (1970). Cognitive capacity and cognitive competence. American Journal of Mental Deficiency, 74, 735-744.

Estes, W.K. (1981). Intelligence and learning. In M.P. Friedman, J.P. Das, \& N. O'Connor (Eds.), Intelligence and learning. New York: Plenum Press.

Doehring, D.G. (1978). On the tangled web of behavioral research on developmental dyslexia. In A.L. Benton \& D. Pearl (Eds.), Dyslexia: An appraisal of current research. New York: Oxford University Press.

Fletcher, J.M., Francis, D.J., \& Morris, R. (1988). Methodological issues in neuropsychology: Classification, measurement, and the comparison of non-equivalent groups. In F. Boller \& J. Grafman (Eds.), Handbook of neuropsychology (Vol. I). Amsterdam: Elsevier.

Fletcher, J.M., \& Morris, R. (1986). Classification of disabled learning: Beyond exclusionary definitions. In S. Ceci (Ed.), Handbook of cognitive, social, and neuropsychological aspects of learning disabilities (Vol. 1, pp. 55-80). Hillsdale, NJ: Erlbaum.

Guilford, J.P. (1967). The nature of human intelligence. New York: McGraw-Hill.

(continued on p. 355) 
cesses in reading (pp. 61-84). Hillsdale, $N J$ : Erlbaum.

Goswami, $U$. (1986). Children's use of analogy in learning to read: $A$ developmental study. Journal of Experimental Child Psychology, 42, 73-83.

Gough, P., \& Hillinger, M.L. (1980). Learning to read: An unnatural act. Bulletin of the Orton Society, 30, 179-196.

Liberman, I.Y., \& Shankweiler, D. (1985). Phonology and the problems of learning to read and write. Remedial and Special Education, 6(6), 8-17.

MacGinitie, W.H. (1978). Gates-MacGinitie reading tests. Boston: Houghton Mifflin.

Mitterer, J.O. (1982). There are at least two kinds of poor readers: Whole word poor readers and recoding poor readers. Canadian Journal of Psychology, 36, 445-461.

Morais, J., Bertelson, P., Cary, L., \& Alegria, J. (1986). Literacy training and speech segmentation. Cognition, 24, 31-44.

Olson, R.K. (1985). Disabled reading processes and cognitive profiles. In D. Gray \& J. Kavanagh (Eds.), Behavioral measures of dyslexia (pp. 215-267). Parkton, MD: York Press.

Perfetti, C.A. (1985). Reading ability. New York: Oxford University Press.

Read, C., Yun-Fei, Z., Hong-Yin, N., \& Bao-Qing, D. (1986). The ability to manipulate speech sounds depends on knowing alphabetic writing. Cognttion, 24, 31-44.
Rosner, J. (1979). Helping children overcome learning disabilities (2nd. ed.). New York: Walker. Stanovich, K.E. (1986). Matthew effects in reading: Some consequences of individual differences in the acquisition of literacy. Reading Research Quarterly, 21, 360-407.

Treiman, R. (1985). Onsets and rimes as units of spoken syllables: Evidence from children. Journal of Experimental Child Psychology, 39, 161-181.

Wagner, R.K., \& Torgesen, J.K. (1987). The nature of phonological processing and its causal role in the acquisition of reading skills. Psychological Bulletin, 101, 192-212. (continued from p. 338)

Jastak, J.L., \& Jastak, S.R. (1965). Wide range achievement test. Wilmington, DE: Guidance Associates.

Jorm, A.F., Share, D.L., MacLean, R., \& Matthews, $R$. (1986). Cognitive factors at school entry predictive of specific reading retardation and general reading backwardness: $A$ research note. Journal of Child Psychology and Psychiatry, 27, 45-54.

Kaufman, A.S. (1979). Intelligent testing with the WISC-R. New York: Academic Press.

Morris, R., \& Fletcher, J.M. (1988). Classification in neuropsychology: $A$ theoretical framework and research paradigm. Journal of Clinical and Experimental Neuropsychology, 10, 640-658.

Morris, R., \& Satz, P. (1986). Classification issues in subtype research: An application of some methods and concepts. In H.A. Whitaker \& R.N. Malatesha (Eds.), Dyslexia: A global issue. New York: Academic Press.

Reynolds, C.R. (1984). Critical measurement issues in learning disabilities. The Journal of Special Education, 18, 451-476.

Rourke, B.P. (1978). Reading, spelling, arithmetic disabilities: A neuropsychologic perspective. In H.R. Myklebust (Ed.), Progress in learning disabilities (Vol. 4, pp. 97-120). New York: Grune \& Stratton.

Rourke, B.P. (1981). Neuropsychological assessment of children with learning disabilities. In S.B. Fikskov \& T.J. Boll (Eds.), Handbook of clinical neuropsychology (pp. 453-478). New York: WileyInterscience.

Rourke, B.P. (1983). Outstanding issues in research on learning disabilities. In M. Rutter (Ed.), Developmental neuropsychiatry (pp. 564-574). New York: Guilford Press.

Rourke, B.P. (Ed.). (1985). Neuropsychology of learning disabilities: Essentials of subtype analysis. New York: Guilford Press.

Rourke, B.P., Fisk, J.L., \& Strang, J.D. (1986). Neuropsychological assessment of children. New York: Guilford Press.

Rutter, M. (1974). Emotional disorder and educational under-achievement. Archives of Disorders in Children, 49, 249-256.
Rutter, M., \& Yule, W. (1975). The concept of specific reading retardation. Journal of Child Psychology and Psychiatry, 16, 181-197.

Sattler, J.M. (1982). Assessment of children's intelligence and special abilities (2nd ed.). Philadelphia: W.B. Saunders.

Shaywitz, S.E., Shaywitz, B.A., Barnes, M., \& Fletcher, J.M. (1986, October). Prevalence of dyslexia in an epidemiological sample. Child Neurology Society.

Taylor, H.G., Fletcher, J.M., \& Satz, P. (1984). Neuropsychological assessment of children. In $G$. Goldstein \& M. Hersen (Eds.), Handbook of psychological assessment (pp. 211-234). New York: Pergamon.

Wechsler, D. (1949). Wechsler intelligence scale for children. New York: Psychological Corp.

Yule, W. (1978). Diagnosis: Developmental psychological assessment. In A.G. Kalverboer, H.M. van Proag, \& J. Mendlewicz (Eds.), Advances in biological psychiatry: Vol. 1, Minimal brain dysfunction: Fact or fiction? Basel: Karger. 